\title{
A Case Study: The Effects of Speed, Agility and Quickness (SAQ) Training Program on Hand-Eye Coordination and Dynamic Balance among Children
}

\author{
Mohamad Nizam Mohamed Shapie* and Raja Nor Farahin Raja Rohizam \\ Faculty of Sports Science and Recreation, Universiti Teknologi MARA (UiTM), Shah Alam, Selangor, Malaysia
}

Submission: March 15, 2018; Published: March 23, 2018

*Corresponding author: Mohamad Nizam Mohamed Shapie, Faculty of Sports Science and Recreation, Universiti Teknologi MARA (UiTM), Malaysia; Email: nizam7907@salam.uitm.edu.my

\begin{abstract}
The purpose of the study was to measure the level of hand-eye coordination and dynamic balance among children by using speed, agility and quickness (SAQ) training program. Sixty primary school children from Klang Valley were randomly assigned into two groups. The participant's age ranged from 7 to 11 years old. The selected participants were divided into two groups which was experimental $(\mathrm{N}=30)$ and control group $(\mathrm{N}=30)$. The experimental group underwent SAQ training program for six weeks with two days training sessions per week. The control group did not participate in SAQ training program. The hand-eye coordination and dynamic balance ability were selected as criterion variables and was tested using ball toss test in order to start execution balance test. All participants of two groups were tested on selected dependent variables at prior and immediately after training program. The data were collected from each participant before and after the training period and statistically analyzed using descriptive and inferential statistics. There were significant improvements due to the effect of SAQ training program on hand-eye coordination and most of the variables tested in dynamic balance among the children. The study also showed that the differences in performance between the experimental and control group were only found in dynamic balance abilities which were left foot for lateral, right foot for posterior and right foot for anterior medial.
\end{abstract}

Keywords: Speed Agility and Quickness (SAQ) training; Hand-eye coordination; Dynamic Balance; Children

Abbreviations: SAQ: Speed Agility and Quickness; SEBT: Start Excursion Balance Test; AL: Anterior Lateral; A: Anterior; AM: Anterior Medial;

M: Medial; PM: Posterior Medial; P: Posterior; PL: Posterior Lateral; L: Lateral

\section{Introduction}

Speed, Agility and Quickness training also known as SAQ training is a system of dynamic movement and guidelines when create the important of motor abilities to enhance the ability of the individual to be more skillful in faster movement. SAQ training may be used physical training to increase the speed, strength or the ability to apply the maximal force during the fast movements [1]. A few benefits of SAQ training consist of increases in muscular power in linear, horizontal and multiplaner movements. It also increased the body spatial awareness, motor skills and reaction of time [2].

Coordination is the ability to use the sense of body such as sight, hearing, and touch together with body parts in performing the motor tasks easily and correctly. Body coordination can describe as the connections or interaction between the muscular, skeletal and nervous systems. Gao et al. [3] stated that hand-eye coordination is important for upper body agility. It is use for vision to guide the movements of the hand such as reaching, moving, catching and grasping. It is require the interact use of eyes, arms, hands and fingers to create the controlled, precise and rapid movement. According to Hollinghurst [4], stated that visual information is use to determine the things and how should the body to be act. As we know, visual feedback helps to give the direction for our hands around problems and align too accurately with the goal. By the training, it will give the flexibility and dexterity of the movement. Then, for the normal hand-eye coordination occur in visual identification of the objective, attention of focusing, perceptual identification and the location of target, cognitive planning and programming of reaching movement.

Balance is the other components in skill related fitness that have ability to stay the upright or stay in the control movement. Balance divided into two which is static and dynamic. Static balance is maintaining the balance in motionless. In this study, focus on the dynamic balance. Bloomfield [5] stated that dynamic balance is the ability to perform the movement and also maintain the body balance while in motion. In dynamic balance, 
our eyes, ears and the all the body sense will help to maintain our balance. In human's condition, both types of balance are main to guarantee a dynamic way of life.

Children enjoy physical activities because it is not only benefit in motor skill coordination and development but also important in fitness and wellness [6]. According to Asonitou et al. [7] stated that children who aged 5 to 11 years old have problem with coordination and their movement. According to Missiuna [8] stated that problem coordination occurs 5 to $6 \%$ of school aged children and tend to occur more frequently in boys. Therefore in response to the problem as stated above, the purpose of this proposed study is to measure the level of handeye coordination and dynamic balance among children by using SAQ training program and to determine the effect of SAQ training program on hand-eye coordination and dynamic balance among children. Thus, the objective of this study was to determine the effect of SAQ training program on hand-eye coordination and dynamic balance among children.

\section{Method}

\section{Participants}

To achieve this purpose of the study, sixty of children studying from Klang Valley were randomly assigned into two groups. The age of the participants ranged from 7 to 11 years old. The selected participants were divided into two groups which were experimental and control group. The experimental group underwent SAQ training program for duration of six weeks with two days per week. In which, the control group did not participate in SAQ training program. The following variable namely hand-eye coordination and dynamic balance ability was selected as criterion variable and was tested by using ball toss and start execution balance test. All participants of two groups were tested on selected dependent variable at prior and immediately after training program.

\section{Procedure}

The procedure of data collection began, in week 1 (day 1) where all participants were informed the purpose of the study. The demographic data were collected from the participants inform consents and PAR-Q. After all participants answered the inform consents and PAR-Q, forms were collected. In week 1 (day 2), all participants performed the pre-test for hand-eye coordination and dynamic balance. All participants were tested individually and each test was performed for three trials. Data were collected after the test and the best result were chosen. Then, in week 2 until week 7, participants in experimental group received six weeks SAQ training program. For the control group they did not received the SAQ training program for the treatment.

The intensity of the training was measured by the heart rate. The low intensity was 110 to 130 heart rate per minute, moderate intensity was 130 to 140 heart rate per minutes and 150 and above for high intensity. The data was collected 2 times in a week which was on Monday and Wednesday. Next, for week 8, all participants performed post-test for hand-eye coordination and dynamic balance test. All participants were tested individually and each test was performed for 3 trials. Data collected and recorded after the test and treatment were performed.

Ball Toss Test was selected for hand-eye coordination. First, the participants stand behind away a line 2 meter from the wall. Then, the ball was tossed on the wall with right hand and was catch back with left hand. Later, the ball was tossed with their left hand and catch back with their right hand. The action was repeated alternated their hand. Time duration for this test was 30 seconds. For the result, how many times the subject catch the ball in 30 seconds. The total catch of the balls in 30 seconds were recorded as the result.

Then, the participant undergoes the start excursion balance test (SEBT). The participants began the test by standing in a square at the center of the grid with 8 lines extending from the center at 45 degree. Each of the 8 lines extending represent the individual directions which each participants required to reach out with the most distal part of their reach foot. The eight directions consist of anterior-lateral $(\mathrm{AL})$, anterior $(\mathrm{A})$, anterior-medial $(\mathrm{AM})$, medial $(\mathrm{M})$, posterior-medial (PM), posterior (P), posterior-lateral (PL) and lateral (L). A standard tape measure $(\mathrm{cm})$ was used to quantify the distance the subject had reached from the centre of the grid to the point that the participants managed to reach along each diagonal line. The test was performed with the subject maintaining a single-leg stance while reaching with the contra lateral leg such as the reach leg. The aim is to reach as far along the 8 directions as possible to touch the furthest point on the line as lightly as possible so as to avoid using the reach leg for support. The subject then returned to the center of the grid on both feet whilst maintaining balance. Participants were given a 5 second rest between each reach. Participants performed three trials and the results were recorded.

\section{Statistical Procedure}

The data were collected from each participant before and after the training period and statistically analyzed by using SPSS version 23.0 and used Independent sample t-test and Paired t-test.

\section{Result}

Table 1 showed the result significant improvement between the pre-test and post-test of hand-eye coordination and most variables in dynamic balance in the experimental group ( $\mathrm{p}<$ 0.05 ) (the participants that participated the 6 weeks SAQ training program). However, there was no significant improvement in anterior for right foot and medial for left foot variables (dynamic balance) ( $p>0.05)$. Table 2 indicated that the improvements of performance between experimental and control group did not showed significant differences $(p>0.05)$ in hand-eye coordination and all dynamic balance abilities except the lateral left foot, posterior right foot and anterior medial right foot. 
Table 1: Comparison Pre-test and Post-test between experimental and control group.

\begin{tabular}{|c|c|c|c|c|c|}
\hline Variable & & $\begin{array}{l}\text { Experimental Group } \\
\qquad(\mathrm{N}=30)\end{array}$ & & $\begin{array}{l}\text { Control Group } \\
\qquad(\mathrm{N}=30)\end{array}$ & \\
\hline & & Pre-Test & Post-Test & Pre-Test & Post-Test \\
\hline & & Mean \pm SD $(\mathrm{cm})$ & Mean \pm SD $(\mathrm{cm})$ & Mean $\pm S D(c m)$ & Mean \pm SD $(\mathrm{cm})$ \\
\hline $\begin{array}{l}\text { Hand-eye } \\
\text { Coordination }\end{array}$ & $\begin{array}{l}\text { Hand-eye } \\
\text { coordination }\end{array}$ & $7.70 \pm 5.91$ & $13.30 \pm 5.54^{*}$ & $14.60 \pm 5.89$ & $19.63 \pm 5.32$ \\
\hline \multirow[t]{16}{*}{ Dynamic Balance } & $\begin{array}{c}\text { Dynamic balance left } \\
\text { anterior }\end{array}$ & $60.00 \pm 11.46$ & $63.00 \pm 11.20^{*}$ & $67.53 \pm 7.94$ & $69.47 \pm 7.52$ \\
\hline & $\begin{array}{l}\text { Dynamic balance } \\
\text { right anterior }\end{array}$ & $61.27 \pm 12.37$ & $62.80 \pm 11.9$ & $67.60 \pm 8.98$ & $68.07 \pm 9.02$ \\
\hline & $\begin{array}{c}\text { Dynamic balance left } \\
\text { anterior lateral }\end{array}$ & $57.17 \pm 11.73$ & $59.53 \pm 11.1^{*}$ & $67.80 \pm 9.13$ & $69.60 \pm 9.40$ \\
\hline & $\begin{array}{l}\text { Dynamic balance } \\
\text { right anterior lateral }\end{array}$ & $57.00 \pm 14.71$ & $58.30 \pm 14.5^{*}$ & $63.90 \pm 9.13$ & $65.97 \pm 8.81$ \\
\hline & $\begin{array}{c}\text { Dynamic balance left } \\
\text { lateral }\end{array}$ & $49.37 \pm 12.79$ & $52.60 \pm 12.24^{*}$ & $65.73 \pm 9.31$ & $60.83 \pm 9.64$ \\
\hline & $\begin{array}{l}\text { Dynamic balance } \\
\text { right lateral }\end{array}$ & $49.27 \pm 13.84$ & $52.43 \pm 11.98^{*}$ & $59.13 \pm 12.27$ & $61.70 \pm 11.80$ \\
\hline & $\begin{array}{c}\text { Dynamic balance left } \\
\text { posterior lateral }\end{array}$ & $45.90 \pm 10.54$ & $48.23 \pm 11.09^{*}$ & $59.73 \pm 9.07$ & $58.10 \pm 8.05$ \\
\hline & $\begin{array}{c}\text { Dynamic balance } \\
\text { right posterior lateral }\end{array}$ & $43.00 \pm 11.91$ & $46.10 \pm 11.28^{*}$ & $56.40 \pm 9.62$ & $65.70 \pm 9.20$ \\
\hline & $\begin{array}{l}\text { Dynamic balance left } \\
\text { posterior }\end{array}$ & $47.37 \pm 11.61$ & $50.53 \pm 11.49 *$ & $64.17 \pm 9.69$ & $66.03 \pm 9.00$ \\
\hline & $\begin{array}{l}\text { Dynamic balance } \\
\text { right posterior }\end{array}$ & $44.30 \pm 10.91$ & $47.50 \pm 11.08^{*}$ & $59.70 \pm 9.10$ & $60.83 \pm 9.68$ \\
\hline & $\begin{array}{c}\text { Dynamic balance left } \\
\text { posterior medial }\end{array}$ & $51.10 \pm 13.74$ & $52.67 \pm 12.64 *$ & $59.27 \pm 9.82$ & $61.70 \pm 9.51$ \\
\hline & $\begin{array}{l}\text { Dynamic balance } \\
\text { right posterior medial }\end{array}$ & $47.03 \pm 10.97$ & $49.00 \pm 10.56^{*}$ & $57.83 \pm 9.78$ & $58.10 \pm 9.77$ \\
\hline & $\begin{array}{l}\text { Dynamic balance left } \\
\text { medial }\end{array}$ & $52.63 \pm 11.82$ & $54.70 \pm 11.35$ & $53.47 \pm 12.36$ & $65.70 \pm 10.79$ \\
\hline & $\begin{array}{l}\text { Dynamic balance } \\
\text { right medial }\end{array}$ & $46.27 \pm 8.75$ & $47.50 \pm 8.04^{*}$ & $54.70 \pm 12.04$ & $59.77 \pm 12.08$ \\
\hline & $\begin{array}{l}\text { Dynamic balance left } \\
\text { anterior medial }\end{array}$ & $51.37 \pm 8.98$ & $53.57 \pm 8.53^{*}$ & $61.67 \pm 9.45$ & $61.40 \pm 8.97$ \\
\hline & $\begin{array}{l}\text { Dynamic balance } \\
\text { right anterior medial }\end{array}$ & $50.63 \pm 10.16$ & $53.00 \pm 9.50^{*}$ & $63.70 \pm 9.34$ & $59.40 \pm 10.14$ \\
\hline
\end{tabular}

*Significance difference between experimental and control group $(p<0.05)$. Dynamic balance was use centimeter (cm) to quantify the distance, Hand-eye coordination was used how many times the catch the ball in 30 seconds.

Table 2: The comparison of differences Hand-eye coordination and Dynamic Balance between experimental and control group.

\begin{tabular}{|c|c|c|c|}
\hline \multirow{2}{*}{ Variable } & & Experimental Group $(\mathrm{N}=30)$ & Control Group $(\mathrm{N}=30)$ \\
\hline & & Mean \pm SD & Mean \pm SD \\
\hline Hand-eye coordination ability & Difference hand-eye coordination & $5.60 \pm 3.46$ & $5.03 \pm 2.77$ \\
\hline \multirow[t]{3}{*}{ Dynamic Balance ability } & $\begin{array}{c}\text { Difference dynamic balance left } \\
\text { anterior }\end{array}$ & $3.00 \pm 2.73$ & $1.93 \pm 3.23$ \\
\hline & $\begin{array}{c}\text { Difference dynamic balance right } \\
\text { anterior }\end{array}$ & $1.53 \pm 2.42$ & $0.47 \pm 3.98$ \\
\hline & $\begin{array}{l}\text { Difference dynamic balance left } \\
\text { anterior lateral }\end{array}$ & $2.37 \pm 2.22$ & $1.80 \pm 3.43$ \\
\hline
\end{tabular}


Journal of Physical Fitness, Medicine \& Treatment in Sports

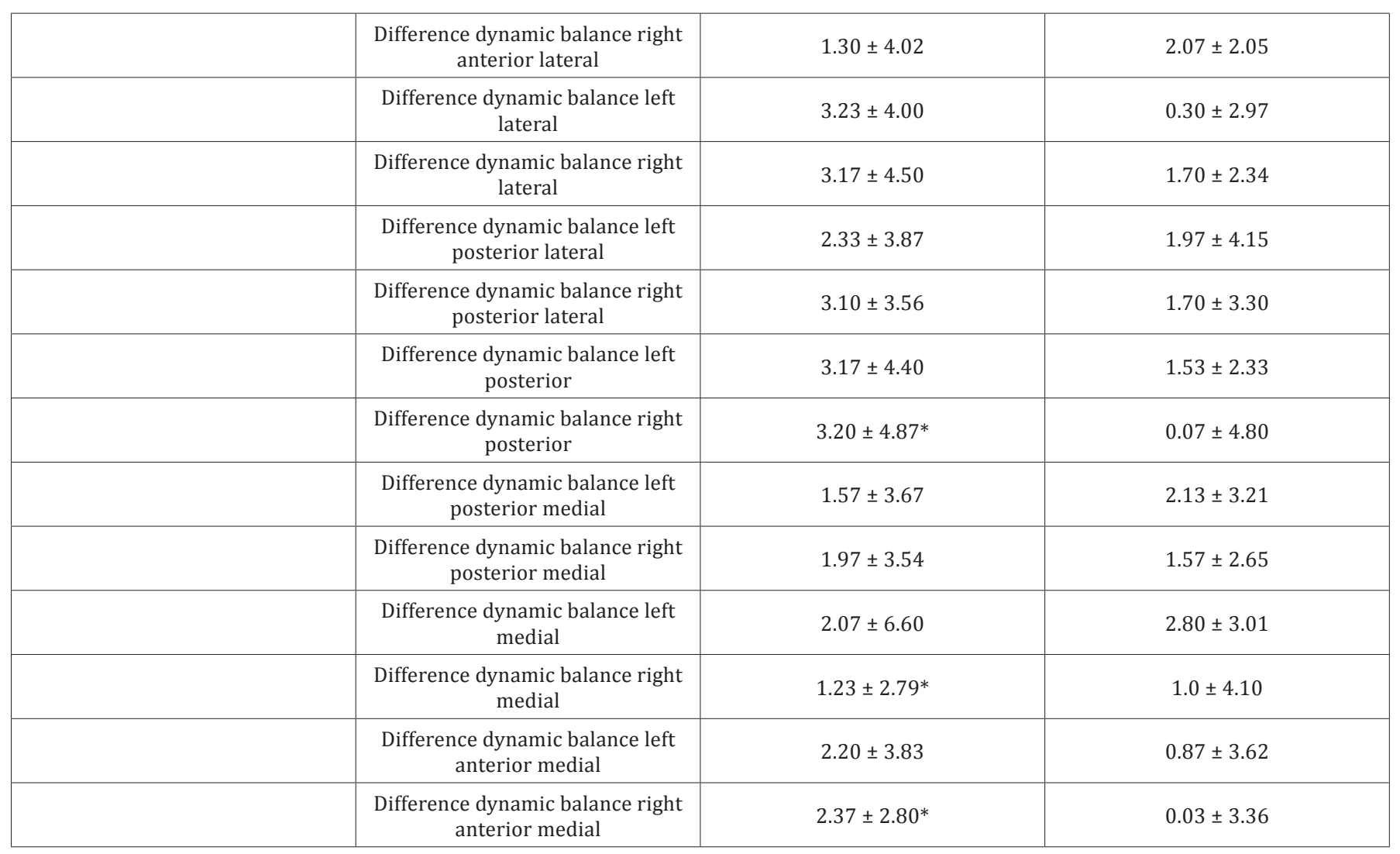

*Significance difference between experimental and control group $(p<0.05)$. Dynamic balance was use centimeter $(\mathrm{cm})$ to quantify the distance, Hand-eye coordination was used how many times the catch the ball in 30 seconds.

\section{Discussion}

Current study showed that there were significant effects of 6-week SAQ training program on the performance of handeye coordination and 14 out of 16 variables of dynamic balance performances in school children aged 7 to 11 years old. Even though, SAQ training program is a problem part in motor coordination, acceleration, balance, agility and reaction developments at all stages and levels of age, current study showed that the training program successfully increased the performance of the children. Velmurugan [1] stated that SAQ training program helped to develop several systems of the human body that required to moving quickly to be more energetic. It is also known the motor abilities that include the balance and coordination control the body movement especially during activities or play the sport. Thus, current study showed that the SAQ training program is an effective way to improve the power of performance in children especially in balance and coordination.

Jelsma et al. [6] showed that the children may have difficulty learning new skill and they found lack of adaptation for learning process. It is suggested that the duration of training should be more than six weeks to show the effects because children who aged 7 to 12 years old have a slow learning process. So they need more time for adaptation process. If the children get more learning time, the higher score will get. However, current study did not support the finding by Jelsma et al. [6] and successfully showed that the 6-week training program was enough to promote the improvement in balance and coordination. Jovanovic et al. [9] stated that to improve the SAQ training program, it has failure to achieve the real level of volume and intensity but it is depending on motivational and effort of individual. It also will enhance the individual capacity through the development and force of execution.

However, the score of improvements (the score of week- 6 minus the score of week-1) between the children that undergone the 6-week training program and control group did not show any significant differences in hand-eye coordination and 14 out of 16 variables of dynamic balance performances. The result for both group in experimental and control group showed no differences performance in dynamic balance such as left and right foot for anterior, left and right foot for anterior lateral, right foot for lateral, left and right foot for posterior lateral, left foot for posterior, left and right foot for posterior medial, left and right foot for medial and left and right foot for anterior medial. The only significant differences of performance between the two groups were on left foot for lateral, right foot for posterior and right foot for anterior medial.

It was speculated that the children in control group were exposed more too physical activity than the children in experimental group. Thus, there was similarity on score 
differences/improvements between both groups that involve in current study. It has been reported that children performances differences tend to be less skill related and more knowledge based $[10,11]$. Both skill and knowledge increase as a result of practice, experience and maturation, however younger children demonstrate less variation in skill than older children and adults. Thus, it was speculated that this similarity in performance was related to knowledge, skill and performance as described by Thomas [12]. They described that novices lack declarative knowledge such as goals and sub goals of the game, rules of the game, offensive and defensive strategies, terminology and etiquette.

\section{Recommendation}

Based on the respond result, there were three recommendations that all parties need to consider;

a) To produce more knowledgeable coaches in the motor learning field for the children. The coaches can implement more technique for children to develop their motor coordination, balance, motor skill and also control their body movement.

b) To suggest the SAQ training program more longer than six weeks (for example in eight weeks) because it can helps in improving the performance a variety of ways. SAQ training program give great benefits that consists of increasing in muscular power in linear, horizontal and multi planer movement. It also increases the body spatial awareness, motor skill and reaction time [2].

c) The variation of the training program (design of the activities) should cater the interest of the children. Variation is one of the principles of training that must be considered when designing training program for athletes. Without this principle of training, the children may lose interest and concentration during training. As a result, it can affect the learning process and will reduce performance improvement.

\section{Conclusion}

In conclusion, the important findings from this study will convince many parties about the important of SAQ training. The study showed that six weeks SAQ training program was enough to improve children performance both in dynamic balance and hand-eye coordination have shown improvement
The SAQ training program should not be underestimated and be informed about the ability of dynamic balance and hand-eye coordination in order to help for performance improvement. All parties including coaches and sport organization should play their important roles to ensure that this SAQ training program become a regular routine in training sessions to achieve goals.

\section{References}

1. Velmurugan G, Palanisamy A (2013) Effects of Saq Training and Plyometric Training on Speed Among College Men Kabaddi Players. Indian Journal of Applied Research 3: 432-433.

2. Nageswaran AS (2013) Effect of SAQ Training on Speed Agility and Balance Among Inter Collegiate Athletes. International Journal of Scientific Research 2(1): 1-2

3. Gao K, Ng SS, Kwok JW, Chow RT, Tsang WW (2010) Eye-hand coordination and its relationship with sensori-motor impairments in stroke survivors. Journal of rehabilitation medicine 42(4): 368-373.

4. Hollinghurst N, Cipolla R (1994) Uncalibrated stereo hand-eye coordination. Image and vision Computing 12(3): 187-192.

5. Bloomfield J, Polman R, O Donoghue P, Mc Naughton L (2007) Effective speed and agility conditioning methodology for random intermittent dynamic type sports. Journal of Strength \& Conditioning Research 21(4): 1093-1100.

6. Jelsma D, Geuze RH, Mombarg R, Smits Engelsman BCM (2014) The impact of Wii Fit intervention on dynamic balance control in children with probable Developmental Coordination Disorder and balance problems. Human Movement Science 33: 404-418.

7. Asonitou K, Koutsouki D, Kourtessis T, Charitou S (2012) Motor and cognitive performance differences between children with and without Developmental Coordination Disorder (DCD). Research in Developmental Disabilities 33(4): 996-1005.

8. Missiuna C, Rivard L, Pollock N (2011) Children with Developmental Coordination Disorder: At home, at school, and in the community, McMaster University, USA

9. Jovanovic M, Sporis G, Omrcen D, Fiorentini F (2011) Effects of speed, agility, quickness training method on power performance in elite soccer players. Journal of Strength \& Conditioning Research 25(5): 12851292.

10. French KE, Thomas JR (1987) The relation of knowledge development to children's Basketball performance. Journal of Sport Psychology 9(1): 15-32.

11. Mc Pherson SL, Thomas JR (1989) Relation of knowledge and performance in boy's tennis: Age and expertise. Journal of Experimental Child Psychology 48(2): 190-211.

12. Thomas KT, Thomas JR (1994) Developing expertise in sport: The Relation of knowledge and performance. International Journal of Sport Psychology 25(3): 295-312. 
This work is licensed under Creative Commons Attribution 4.0 License

DOI: $10.19080 / J P F M T S .2018 .02 .555591$
Your next submission with Juniper Publishers will reach you the below assets

- Quality Editorial service

- Swift Peer Review

- Reprints availability

- E-prints Service

- Manuscript Podcast for convenient understanding

- Global attainment for your research

- Manuscript accessibility in different formats ( Pdf, E-pub, Full Text, Audio)

- Unceasing customer service

Track the below URL for one-step submission https://juniperpublishers.com/online-submission.php 